\title{
Dynamic Capabilities and Competitive Advantage of Telecommunication Companies in Ghana. The Role of Innovation Capability
}

Nana Esi Quagraine" ${ }^{11}$, Cai Li ${ }^{1}$, Isaac Ahakwa ${ }^{1}$, Nana Aba Quagraine ${ }^{2}$

${ }^{*}$ School of Management, Jiangsu University, Zhenjiang, China

${ }^{2} \mathrm{~S}$ chool of Business, University of Ghana, Accra, Ghana

\begin{abstract}
Article Info

Volume 7, Issue 3

Page Number: $146-160$

Publication Issue :

May-June-2021

\section{Article History}

Accepted : 10 May 2021

Published : 15 May 2021

This paper explored the link between dynamic capabilities, innovation capabilities, and competitive advantage of telecommunication companies in Ghana, considering a mediation interaction. Data were obtained from two hundred and fifty (250) employees from selected telecommunication companies in the Accra metropolis through simple random probability sampling. However, two hundred and forty-two (242) responses were deemed accurate and used in the analysis. Partial Least Squares (PLS) based on Structural Equation Modeling (SEM) was employed in the analysis. From the findings, this study's data met internal consistency reliability, convergent, and discriminant validity. Dynamic capabilities had a positive and significant impact on innovation capability and competitive advantage. Also, dynamic capabilities through innovation capability positively impacted competitive advantage and were statistically significant. Based on the findings, it's recommended that organizations and managers consider both exploitation and exploration competencies in product development as both competencies influence various aspects of an organization's competitive advantage, as this will help ensure organizations' sustainable performance and thus remain competitive.
\end{abstract}

Keywords : Exploitation, Exploration, Innovation Capability, Competitive Advantage, Ghana.

\section{INTRODUCTION}

World economies are becoming more and more difficult for companies. Firms face the uncertainty and speed of transition daily, as well as the globalization of demanding consumers and hypercompetition [1]. Product development and innovation are essential to businesses' sustainability and growth, as they will help fulfill consumer needs and requirements than current offers [2]. Innovation is essential in companies where companies are confronted with greater complexity and competition for new product shares [3]. Teece, Pisano [4] proposed a dynamic capabilities concept for addressing the essential task of building, integrating, and reconfiguring resources in an extremely volatile environment. Therefore, the possession of dynamic capabilities in the circumstances involving dynamic and rapidly changing conditions makes firm competition more effective [5-7]. 
There are various studies on dynamic capabilities, innovation, and competitive advantage. For, e.g., Adeniran and Johnston [8] researched dynamic capabilities and competitive advantage of SMEs in South Africa. From the result, dynamic capabilities positively and significantly impact competitive advantage. Li and Liu [9] delved into the interaction between dynamic capability and competitive advantage in China. It was reported from the findings that there was a strong association between dynamic capability and competitive advantage. Kiiru [10] examined the influence of dynamic capabilities and competitive advantage of SMEs in Kenya. The findings indicated that competitive advantage is achieved through a successful deployment of dynamic strategic capabilities. [11] also looked into the relationship between innovation and competitive advantage in Jordan's education sector. The outcome revealed that competitive advantage is achieved through the adoption of innovation capabilities. The studies mentioned above, among others, are inadequate as Ghana has not been considered a country. To the best of our knowledge, the bulk of management research on dynamic capabilities and competitive advantages is more connected to SMEs and other companies at the expense of telecommunication organizations. This research contributes to filling this gap by concentrating on telecommunications organizations. The report adds to the present literature as follows:

First, while prior studies clearly show the role of exploitative and exploration capacities in companies' success, most of the studies focus on technology and product development capability. Yet, innovation covers other aspects too. The exclusive emphasis on technology and product growth reduces awareness of the importance of exploitative and exploration capabilities in successfully launching and disseminating innovation. This study helps fill the gap by investigating the drivers and competitive advantage outcomes of market-related exploitative and explorative capabilities, along with product development ones. Second, numerous studies on dynamic capabilities and competitive advantage have been done. However, only a small number of those studies considered mediation interaction in their model. To the best of our knowledge upon an extant review of the literature, this is the first study to report the mediation role of innovation capability in the Ghanaian context between dynamic capability and competitive advantage. Last, most previous studies delved into the relations between dynamic capabilities and competitive advantage using partial least squares (PLS) focused on structural equation modeling (SEM). This study used the current method of assessing the model's predictive relevance, "the PLSpredict" proposed by [12, 13], which is not common in existing studies.

The contributions mentioned above are novel since they are deficient in dynamic capabilities and competitive advantage studies undertaken in the Ghanaian context. The study is eventually unique since the investigators themselves carried it out; the study's hypothesis and intent are clearly defined; the techniques used are fully detailed; the findings are properly represented, and the practical implications are properly explained. The rest of the report is organized as follows: the "Literature Review" section presents the literature promoting the subject under study, while the "Method and Material" part reflects the study technique. Empirical findings of the analysis are summarized in the "Results" section, while discussions, practical implications, limitations and recommendations are the final section of the research. 


\section{LITERATURE REVIEW}

\subsection{Exploitation and exploration and competitive advantage.}

The company's goal is to develop products, build and sustain relationships with export customers, and get timely input from them [5]. Exploratory and exploitative abilities have different logics, but they are interconnected and compatible. Exploitation helps maintain existing viability, while exploration helps maintain potential viability [14]. Exploratory capability can then be built on top of exploitative capabilities [15]. Nonetheless, profit is an essential aspect of an organization's growth [16]. Refinement and gradual enhancements are the focus of exploitative capabilities. Exploitative capabilities add to an organization's short-term growth by exploiting its existing goods and customers and aiding in the transition to the new operating climate [17]. Exploratory skills enable the company to refresh its resource base regularly and expect demand trends ahead of time. In changing environment, acquiring, incorporating, and reconfigure resources in ways that balance the markets reinforces a long-term strategic advantage [18]. Innovative skills such as research and exploitation help firms maintain their competitive advantage and success [19]. Current paradigms are optimized by exploitative capabilities [20]. In this way, the creative mechanism is critical for organizations to achieve business stability and retain a competitive edge. Many research categorizes innovation according to how information is implemented, accessed, and reused [21]. Explorative innovation seeks to create variety by looking for and obtaining unfamiliar and innovative tools and materials. The accumulation of fresh information that supports the development of innovation by exploration would be limited due to the degree of primary knowledge [22]. Exploitative innovation is used to satisfy the demands of consumers and current markets, as well as to extend prevailing current goods and services and refine and improve process performance. In contrast to explorative innovation, exploratory innovation is focused on experience and expertise linked to key knowledge and skills [23].

2.2 Exploitation and exploration and innovation capability.

Earlier research has identified the two key instances of organizational learning, and this includes enhancing one's skills in exploitative learning and gaining fresh knowledge by explorative learning [3, 24, 25]. Current product enhancements are exploitative capabilities, while market-related exploitative capabilities include strengthening partnerships in prevailing markets. Search and use of new choices are the explorative capabilities [26]. They are similar to IC, while industry-related explorative skills include establishing new business partnerships. These are prerequisites for organizational preparation and skill growth in general and creative skills [27]. According to [28], exploration and exploitation practices reveal the invention procedure's essence rather than the result's nature. We take these authors' advice and describe discovery and exploitation practices in terms of the innovation process. Exploration and exploitation practices will also be part of an innovation phase [26]. According to previous studies, exploration and exploitation practices play various roles in the innovation procedure and affect different innovation outcomes. Exploration appears to be more crucial for enhancing distinct and innovative results, while exploitation appears to be more likely to lead to cost savings and benefit gains, output effectiveness, and consistency [29-31].

\subsection{Innovation and competitive advantage}

Individual creativity and innovativeness are critical to corporate growth, and individual creativity and innovativeness are critical to the organizational level of innovation [32, 33]. "The method of identifying a fresh or changing the organization's current 
operating system" or "the unearthing of a radically different market concept in an existing business" [34]. Innovation capability is regarded as a valuable tool that helps companies achieve and retain a competitive edge while promoting the overall plan's execution. It is blended into a firm's core operations [34] and cannot be isolated from other activities. It helps companies rapidly launch new goods and incorporate new processes, making it vital in countering ongoing competition. According to [35], innovation capability allows companies to apply acceptable process technology to produce new goods that fulfill consumer demands while eliminating competitive risks. It aids in shaping and managing the firm's various skills to promote combining capabilities and stimulate effective innovation [36]. Vicente, Abrantes [37] described innovation capability as a company's ability to produce innovative products by combining innovation, strategic capability, and internal technical processes. According to Urbancova [38], innovation is the product of an organization's employees' ingenuity, and it must always be centered on the consumer and add value. As a result, it's critical to understand that the creative component is dependent on people's expertise, talents, and skill [39]. People produce ideas built on observations of exterior and interior circumstances that can help a company achieve a strategic edge and thereby differentiate itself from its rivals, at least for a limited time.

Based upon the literature discussion, we established the following hypotheses;

H1: Exploitation positively and significantly influences competitive advantage.

H2: Exploration positively and significantly affects competitive advantage.

H3: Exploitation positively and significantly impacts innovation capability.

H4: Exploration positively and significantly influences innovation capability.
H5: Innovation capability significantly influences competitive advantage.

H6: Innovation capability significantly mediates the association between exploitation and competitive advantage.

H7: Innovation capability significantly mediates the link between exploration and competitive advantage.

\subsection{The Conceptual Framework}

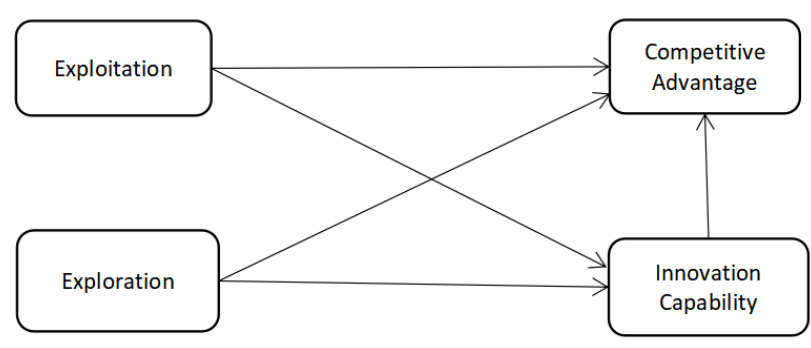

Figure 1: Conceptual framework

\section{METHODS AND MATERIAL}

\subsection{Research design}

A research design is a collection of procedures and techniques used to capture and analyze the measurements of factors recognized in a research problem [40]. To evaluate classification features, quantify numbers, and construct a predictive pattern to test hypotheses and explain results, the research used quantitative approaches.

\subsection{Research population}

The population of research refers to the complete group of objects or individuals essential to the research project [41]. The population considered by the study were employees from top established telecommunications companies in the Accra metropolis of Ghana (MTN, AirtelTigo, and Vodafone). 


\subsection{Research sampling and sample size.}

The sampling applies to an approach to choosing a part of the sample population that will represent the whole study population. This research followed a simple random sampling technique where every person was given an equal opportunity to answer the questions asked. The sample size used for the analysis is two hundred and fifty (250), all of whom were employees at the selected telecommunication companies.

\subsection{Data instrument and collection.}

To achieve the objectives of the study, the researcher gathered information from the study population. The research used the questionnaire as a medium to request information from the population. The questionnaire included questions related to the participants' demographic characteristics. There were questions in the second part of the questionnaire that helped examine the variables to be evaluated. The source of the items and the number of items used to measure this study's variables are presented in Table 1. Participants were called upon to rate the questions based on the 5-point Likert with the scaling pole ranging from strongly disagree (1) to strongly agree (5). Two hundred and fifty (250) online questionnaires were sent to respondents through various digital platforms. Two hundred and forty-two (242) were deemed fit and accurate, then used for discussion.

TABLE 1

MEASUREMENT OF VARIABLES

\begin{tabular}{|l|c|c|}
\hline Constructs & $\begin{array}{c}\text { Number } \\
\text { of Items }\end{array}$ & Literature Source \\
\hline $\begin{array}{l}\text { Competitive } \\
\text { Advantage }\end{array}$ & 4 & {$[42]$} \\
\hline $\begin{array}{l}\text { Innovation } \\
\text { Capability }\end{array}$ & 4 & {$[43]$} \\
\hline Exploitation & 4 & {$[44]$} \\
\hline Exploration & 4 & {$[44]$} \\
\hline
\end{tabular}

\subsection{Data analysis.}

Data was moved from the online survey questionnaire portal to the Microsoft Excel format for easy access and transition to the various research tools. The research involved exploratory and confirmatory studies in confirming the validity of the model. SPSS version 26.0 was used to process descriptive statistics to assess the demographic profile of the samples. Partial Least Squares (PLS) analysis using SmartPLS 3.0 software was used to evaluate the research model. The measurement model was tested for the validity and reliability of the constructs. The structural model was then analyzed in conjunction with the two-stage analytical procedures suggested for SEM [45]. A bootstrapping method (5000 resamples) was used to test the path coefficients' significance and loadings [45].

\section{RESULTS AND DISCUSSION}

\subsection{Demographic Information}

TABLE 2

RESPONDENT'S PROFILE

\begin{tabular}{|c|c|c|}
\hline $\begin{array}{c}\text { Demographic } \\
\text { Characteristics }\end{array}$ & & $\%$ \\
\hline \multirow{4}{*}{ Gender } & Male & 42.9 \\
\cline { 2 - 3 } & Female & 57.1 \\
\hline \multirow{4}{*}{ Age } & $18-25$ years & 38.2 \\
\cline { 2 - 3 } & $26-35$ years & 35.9 \\
\cline { 2 - 3 } & $36-45$ years & 18.5 \\
\cline { 2 - 3 } & 46 years and above & 7.4 \\
\hline \multirow{4}{*}{ Qualification } & Diploma certificate & 18.5 \\
\cline { 2 - 3 } & Bachelor degree & 60.5 \\
\cline { 2 - 3 } & Post-graduate degree & 20.0 \\
\cline { 2 - 3 } & Other certificates & 1.0 \\
\hline \multirow{4}{*}{ Work } & Less than one year & 4.8 \\
\cline { 2 - 3 } & Between 1 to 2 years & 13.8 \\
\cline { 2 - 3 } & Between 2 to 5 years & 65.4 \\
\cline { 2 - 3 } & Above five years & 16.0 \\
\hline
\end{tabular}

Respondents' descriptive statistics showed that $42.9 \%$ of the overall response are males, while females accounted for $57.1 \%$. The findings also revealed that $38.2 \%$ of those respondents were 18 to 25 years of age, 
$35.9 \%$ were 26 to 35 years of age, $18.5 \%$ were 36 to 45 years of age, while $7.4 \%$ were 46 years of age or older. The demographic findings showed that $4.8 \%$ had below one year of work experience at their present organizations, $13.8 \%$ had $1-2$ years of experience, $65.4 \%$ had 2-5 years of work experience, and $16.0 \%$ had more than five years of work experience. Finally, Table 2 indicates that $18.5 \%$ of respondents had a diploma certificate, $60.5 \%$ had a bachelor's degree, $20.0 \%$ had a post-graduate degree (either a master's degree or a doctoral degree), 1.0\% had other certificates.

\subsection{Measurement Model Assessment}

Table 3 displays the values of Factor Loading, Cronbach Alpha, Composite Reliability (CR), and Average Variance Extracted (AVE) after confirmatory factor analysis for all latent constructs. All the item loadings were above the threshold of 0.6 [46]. The item loadings ranged from 0.718-0.928. The Cronbach alpha, which is the measure of internal consistency of the set of items, surpassed the suggested value of 0.70 [45]. Composite reliability values, presenting the amount at which the construct indicators show the latent construct, surpassed the threshold value of 0.7 while average variance extracted, reflecting the full measure of variance in the indicators of the latent construct, surpassed the suggested value of 0.5 [45]. Having met the above minimum threshold requirements proposed by [45] and [46] for the internal consistency and reliability checks, we can conclude that the model is accurate enough for the analysis.
TABLE 3

CONSTRUCT RELIABILITY AND VALIDITY

\begin{tabular}{|c|c|c|c|c|c|}
\hline Variables & INT & FLD & a & CR & AVE \\
\hline \multirow{4}{*}{$\begin{array}{l}\text { Competitive } \\
\text { Advantage }\end{array}$} & CA1 & 0.718 & \multirow{4}{*}{0.795} & \multirow{4}{*}{0.867} & \multirow{4}{*}{0.620} \\
\hline & CA2 & 0.800 & & & \\
\hline & CA3 & 0.799 & & & \\
\hline & CA4 & 0.823 & & & \\
\hline \multirow{4}{*}{$\begin{array}{l}\text { Innovation } \\
\text { Capability }\end{array}$} & IC1 & 0.794 & \multirow{4}{*}{0.834} & \multirow{4}{*}{0.889} & \multirow{4}{*}{0.667} \\
\hline & IC2 & 0.801 & & & \\
\hline & IC3 & 0.841 & & & \\
\hline & IC4 & 0.830 & & & \\
\hline \multirow{4}{*}{ Exploitation } & ET1 & 0.891 & \multirow{4}{*}{0.871} & \multirow{4}{*}{0.912} & \multirow{4}{*}{0.722} \\
\hline & ET2 & 0.821 & & & \\
\hline & ET3 & 0.928 & & & \\
\hline & ET4 & 0.750 & & & \\
\hline \multirow{4}{*}{ Exploration } & ER1 & 0.847 & \multirow{4}{*}{0.852} & \multirow{4}{*}{0.900} & \multirow{4}{*}{0.691} \\
\hline & ER2 & 0.800 & & & \\
\hline & ER3 & 0.850 & & & \\
\hline & ER4 & 0.828 & & & \\
\hline
\end{tabular}

*Note: ET (exploitation), ER (exploration), IC (innovation capability), CA (competitive advantage), INT (Indicators), $\alpha$ (Cronbach alpha), FLD (Factor loadings)

TABLE 4

MULTI-COLLINEARITY TEST RESULT

\begin{tabular}{|c|c|}
\hline Indicators & VIF \\
\hline CA1 & 1.372 \\
\hline CA2 & 1.895 \\
\hline CA3 & 1.601 \\
\hline CA4 & 1.849 \\
\hline ER1 & 1.941 \\
\hline ER2 & 1.788 \\
\hline ER3 & 2.309 \\
\hline ER4 & 1.829 \\
\hline ET1 & 3.242 \\
\hline ET2 & 1.823 \\
\hline ET3 & 3.012 \\
\hline ET4 & 1.764 \\
\hline IC1 & 1.716 \\
\hline IC2 & 1.808 \\
\hline
\end{tabular}




\begin{tabular}{|c|c|}
\hline IC3 & 1.927 \\
\hline IC4 & 1.884 \\
\hline
\end{tabular}

*Note: ET (exploitation), ER (exploration), IC (innovation capability), CA (competitive advantage)

Because multi-collinearity may end in excessive assurance intervals and smaller reliable probability figures, culminating in distorted or false implications [47], the investigators wanted to determine if the variables were strongly linked or not. Multicollinearity was observed using the Variance Inflation Factor (VIF). A variable or an indicator with a VIF larger than 5 (VIF>5) was judged strongly collinear with all other variables. The VIFs of all the items or indicators in Table 4 implied that the factors were unrelated, suggesting no collinearity problems in the model [48]. This means that all of the factors are competent to be used together in this research.

TABLE 5

FORNELL-LARCKER'S DISCRIMINANT VALIDITY

\begin{tabular}{|l|c|c|c|c|}
\hline Variables & 1 & 2 & 3 & 4 \\
\hline $\begin{array}{l}\text { Competitive } \\
\text { Advantage }\end{array}$ & $\mathbf{0 . 7 8 8}$ & & & \\
\hline Exploitation & 0.137 & $\mathbf{0 . 8 5 0}$ & & \\
\hline Exploration & 0.418 & 0.120 & $\mathbf{0 . 8 3 1}$ & \\
\hline $\begin{array}{l}\text { Innovation } \\
\text { Capability }\end{array}$ & 0.544 & 0.190 & 0.515 & $\mathbf{0 . 8 1 7}$ \\
\hline
\end{tabular}

In determining the discriminant validity, which represents the degree to which the measures are not replicating some other variables, low connections between the measure of interest and other constructs' measures are indicated. Table 5 confirms that each construct's AVE square root (diagonal values) is greater than its corresponding correlation coefficients, suggesting sufficient discriminant validity [49].
TABLE 6

HETEROTRAIT-MONOTRAIT RATIO (HTMT) FOR DISCRIMINANT VALIDITY

\begin{tabular}{|l|c|c|c|c|}
\hline Variables & 1 & 2 & 3 & 4 \\
\hline Competitive Advantage & & & & \\
\hline Exploitation & 0.171 & & & \\
\hline Exploration & 0.498 & 0.135 & & \\
\hline Innovation Capability & 0.660 & 0.217 & 0.595 & \\
\hline
\end{tabular}

Current disapproval of the Fornell and Larcker [49] criteria indicates that they do not effectively identify an absence of discriminant validity [50]. Henseler, Ringle [50] advocated a substitute method to measure the discrimination validity of the HTMT ratio of correlation built on the multi-trait-multimethod matrix. This new method was used to check the discriminant validity, and the findings are presented in Table 6. When the HTMT value for the first criterion is larger than the threshold value of 0.85 [51], there is a problem with discriminant validity. However, as presented in Table 6, all the values were below the HTMT value of 0.85 .

\section{Structural Model Assessment}

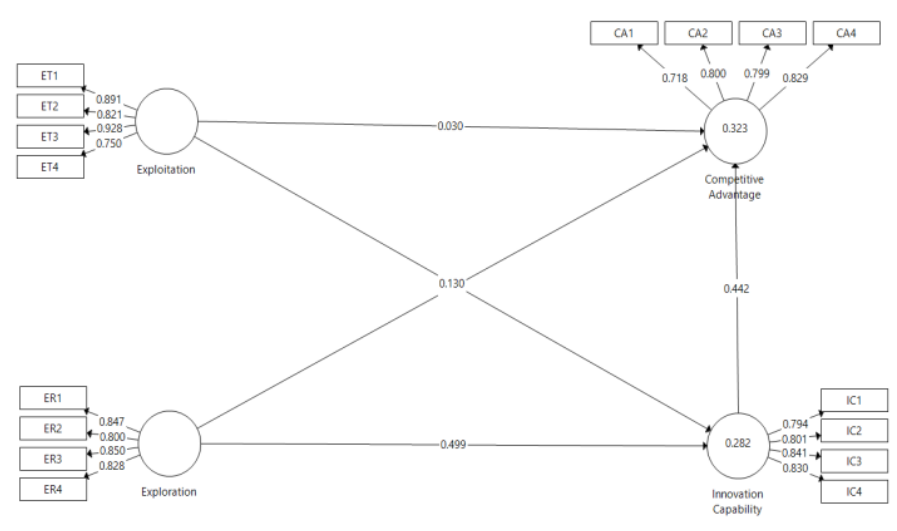

Figure 2 : Structural model 
TABLE 7

HYPOTHESIS TESTING (DIRECT RELATIONSHIP)

\begin{tabular}{|l|l|c|c|c|c|c|}
\hline $\mathrm{M}$ & Relationship & $\beta$ & $\mathrm{t}$-value & $\mathrm{p}$-value & $f^{2}$ & Decision \\
\hline Path & ET $\rightarrow$ CA & 0.030 & 2.231 & $0.034^{\mathrm{b}}$ & 0.021 & Supported \\
\hline & ER $\rightarrow$ CA & 0.186 & 2.701 & $0.007^{\mathrm{a}}$ & 0.038 & Supported \\
\hline & ET $\rightarrow$ IC & 0.130 & 2.533 & $0.011^{\mathrm{b}}$ & 0.023 & Supported \\
\hline & ER $\rightarrow$ IC & 0.499 & 10.098 & $0.000^{\mathrm{a}}$ & 0.342 & Supported \\
\hline & IC $\rightarrow \mathrm{CA}$ & 0.442 & 6.415 & $0.000^{\mathrm{a}}$ & 0.208 & Supported \\
\hline$R^{2}$ & CA & 0.323 & & & & \\
\hline & IC & 0.282 & & & & \\
\hline$Q^{2}$ & CA & 0.183 & & & & \\
\hline & IC & 0.170 & & & & \\
\hline
\end{tabular}

Note: ${ }^{a},{ }^{b}$ denote significance at $1 \%$ and $5 \%$ level respectively, $\beta$ (path coefficient), SD (standard deviation), ET (exploitation), ER (exploration), IC (innovation capability), CA (competitive advantage)

TABLE 8

HYPOTHESES TESTING (INDIRECT RELATIONSHIP)

\begin{tabular}{|l|c|c|c|c|c|}
\hline $\begin{array}{l}\text { Relationshi } \\
\text { ps }\end{array}$ & $\beta$ & $\begin{array}{c}\mathrm{t}- \\
\text { value }\end{array}$ & $\begin{array}{c}\mathrm{p}^{-} \\
\text {value }\end{array}$ & $\begin{array}{c}\text { Decisio } \\
\mathrm{n}\end{array}$ & $\begin{array}{c}\text { Medi } \\
\text { ation } \\
\text { type }\end{array}$ \\
\hline $\begin{array}{l}\mathrm{ET} \rightarrow \mathrm{IC} \rightarrow \\
\mathrm{CA}\end{array}$ & $\begin{array}{c}0.05 \\
8\end{array}$ & 2.293 & $\begin{array}{c}0.022 \\
\mathrm{~b}\end{array}$ & $\begin{array}{c}\text { Support } \\
\text { ed }\end{array}$ & $\mathrm{PM}$ \\
\hline $\begin{array}{l}\mathrm{ER} \rightarrow \mathrm{IC} \rightarrow \\
\mathrm{CA}\end{array}$ & $\begin{array}{c}0.22 \\
1\end{array}$ & 5.302 & $\begin{array}{c}0.000 \\
\mathrm{a}\end{array}$ & $\begin{array}{c}\text { Support } \\
\text { ed }\end{array}$ & $\mathrm{PM}$ \\
\hline
\end{tabular}

Note: ${ }^{a}$, b denote significance at $1 \%$ and $5 \%$ level respectively, $\beta$ (path coefficient), SD (standard deviation), ET (exploitation), ER (exploration), IC (innovation capability), CA (competitive advantage), PM (partial mediation)

We assessed the direct relationships between the variables. Table 7 reveals, first $\mathrm{H} 1[\mathrm{ET} \rightarrow \mathrm{CA}]$; is supported $(\beta=0.030 ; \mathrm{t}$-value $=2.231, \mathrm{p}<0.05)$. This finding indicates that exploitation significantly influence competitive advantage. Second, H2 [ER $\rightarrow$ $\mathrm{CA}$ ); is supported $(\beta=0.186$; $\mathrm{t}$-value $=2.701, \mathrm{p}<0.01)$. This finding implies that exploration positively and significantly influence competitive advantage. Third, $\mathrm{H} 3$ [ET $\rightarrow \mathrm{IC}$; is supported $(\beta=0.130$; $\mathrm{t}$-value $=2.533$, $\mathrm{p}$ $<0.05)$. This finding denotes that exploitation positively and significantly influence innovation capability. Fourth, H4 [ER $\rightarrow$ IC] is supported $(\beta=0.499 ; \mathrm{t}$-value $=10.098, \mathrm{p}<0.05)$. This finding suggests that exploration significantly influence innovation capability. Last, H5 [IC $\rightarrow$ CA]; is supported $(\beta=0.442 ; \mathrm{t}$-value $=6.415, \mathrm{p}<0.01)$. This finding infers that innovation capability positively and significantly influence competitive advantage.

We also assessed the indirect relationship amid the variables. Table 8 reveals that $\mathrm{H6}[\mathrm{ET} \rightarrow \mathrm{IC} \rightarrow \mathrm{CA}]$; is supported $(\beta=0.058 ; \mathrm{t}$-value=2.293, $\mathrm{p}<0.05)$. The findings revealed that innovation capability partially mediates the link between exploitation and competitive advantage. Also, $\mathrm{H} 7$ [ER $\rightarrow \mathrm{IC} \rightarrow \mathrm{CA}$ ]; is supported $(\beta=0.221 ; \mathrm{t}$-value=5.302, $\mathrm{p}<0.01)$. The findings revealed that innovation capability partially mediates the connection between exploration and competitive advantage.

Next, we assessed the effect sizes $\left(f^{2}\right)$. Cohen's (1988) guidelines were used to measure the effect size, which are 0.02 for small effects, 0.15 for medium effects, and 0.35 for strong effects. Table 7 shows that exploration had the most strong positive effect on innovation capability with an $f^{2}$ value of 0.342 , followed by innovation capability with a significant positive strong effect on competitive advantage with an $f^{2}$ value of 0.208 . Moreover, both exploration and exploitation had a significant medium effect on competitive advantage, respectively. Last, the exploitation had a significant medium influence on innovation capability with an effect size value of 0.023 . 
Table 7 discloses the $R^{2}$, which is the total amount of explained variance in the endogenous constructs'. Therefore, the $R^{2}$ of competitive advantage and innovation capability are 0.323 and 0.282 , respectively. This implies that exploitation and exploration explain $32.3 \%$ and $28.2 \%$ of the total variance in competitive advantage and innovation capability, respectively. This study's $R^{2}$ values are higher than the threshold value of 0.26 proposed by Cohen [52], indicating that the model is substantial.

The predictive sample reuse technique $\left(Q^{2}\right)$, in addition to the size effect of the $R^{2}$ and $f^{2}$, can effectively demonstrate predictive relevance [46]. Based on the blindfolding technique, $Q^{2}$ displays how well data can be reassembled empirically through the model and the PLS parameters. For this study, we acquired our $Q^{2}$ through cross-validated redundancy procedures. A $Q^{2}$ value bigger than zero $(0)$ means that the model has predictive relevance; however, a $Q^{2}$ value below 0 means the model's predictive relevance lacks. Therefore, our $Q^{2}$ values of 0.183 and 0.170 in table 7 suggested that the model had acceptable predictive relevance.

TABLE 9

PLS PREDICT

\begin{tabular}{|l|c|c|c|c|}
\hline Indicators & $\begin{array}{c}Q^{2} \\
\text { predict }\end{array}$ & $\begin{array}{c}\text { PLS- } \\
\text { RMSE }\end{array}$ & $\begin{array}{c}\text { LM- } \\
\text { RMSE }\end{array}$ & $\begin{array}{c}\text { (PLS- } \\
\text { RMSE)- } \\
\text { (LM-RMSE) }\end{array}$ \\
\hline CA1 & 0.057 & 0.687 & 0.698 & -0.011 \\
\hline CA2 & 0.128 & 0.698 & 0.716 & -0.018 \\
\hline CA3 & 0.107 & 0.577 & 0.582 & -0.005 \\
\hline CA4 & 0.106 & 0.718 & 0.722 & -0.004 \\
\hline IC1 & 0.099 & 0.571 & 0.575 & -0.004 \\
\hline IC2 & 0.124 & 0.722 & 0.726 & -0.004 \\
\hline IC3 & 0.204 & 0.611 & 0.626 & -0.015 \\
\hline IC4 & 0.262 & 0.669 & 0.678 & -0.009 \\
\hline
\end{tabular}

Note: RMSE: Root Mean Squared Error; LM: Linear Regression Model
We followed the recommended guideline in assessing the prediction error degree [12]. We first evaluated the PLS-SEM $Q^{2}$ predict values for all the indicators of the measurement model. Table 10 reveals that all the $Q^{2}$ predict values are greater than zero (0), indicating a highly symmetrical distribution of prediction errors. We then compared the naive LMRMSE with the PLS-RMSE values of the PLS-SEM analysis; the PLS-SEM analysis produces lower forecast errors for all indicators. For example, for the model estimation using PLS-SEMs, RMSE values of CA1, CA2, CA3, and CA4 are 0.687, 0.698, 0.577, and 0.718, whereas, for these indicators, LM produces RMSE values of $0.698,0.716,0.582$, and 0.722 respectively. Therefore, the negative values in table 9 for all the indicators show that the model has a high predictive power since all the PLS-RMSE indicators are less than the naïve LM-RMSE values [53]

\section{DISCUSSION AND RECOMMENDATION}

Exploration has a positive impact on competitive advantage, as well, exploitation has a positive impact on competitive advantage. These findings are consistent with previous research. Thus, a company's long-term competitiveness can be determined by its ability to integrate and expand on existing competencies while still creating radically novel ones [54]. Concurrent investments in exploiting current product innovation capabilities and exploring new ones can generate a competitive advantage [26]. Exploration and exploitation are widely used to describe practices vital to a company's ability to retain and enhance its competitive edge [55]. According to the literature, organizational learning is stressed as an essential consideration for realizing an organization's competitive advantages as a means of information formation and knowledge as a special, inimitable, and limitless resource [56]. It is also recognized as a vital factor in securing a long-term 
strategic edge and increased firm efficiency [57]. An earlier study has shown the effects of cooperation and Team learning, ongoing learning, inquiry, dialogue, empowering people, organizational connection with their environment, and leadership support on the financial performance dimension and the connection amid organizational and financial practices [3].

This study reveals that exploitation positively impacts innovation capabilities, and exploration also positively impacts innovation capabilities. Thereby, exploitation and exploitation have significant influences on innovation capabilities. These findings are consistent with previous literature that suggest that exploitation and exploration are radically diverse logics that generate conflict by competing with the finite capital and strategic emphasis on innovation of companies [58]. These findings are also consistent with that literature that views the sustainable competitive advantage in dynamic economies as a function of companies' willingness to integrate and reconfigure resources according to consumer requirements [59]. This is a statistically important relationship for both groups and demonstrates that innovation is crucial in organizations with increasing volatility and competition from companies for new products $[3,60]$. Exploration and exploration are the most critical to innovation capability [61]. Exploitation involves improving current skills, and exploration addresses existing concepts [26].

Innovation capability has a significant impact on competitive advantage. This is consistent with a recent study, which indicates that creativity is a special advantage of a business and has positive and greater implications for competitive advantage. Indeed, a study in the past decade has shown an analytical relation of innovation, competitive advantages, and implicitly an organization's success $[62,63]$. Innovation is one of the major tools for growing market share and supplying the firms with a strategic edge, positively affecting business performance, gaining a stronger marketplace, and competitive advantage and superior performance [64]. By good innovation, consumers are paying a prize and buy more often and are therefore faithful to the business when products/services are bought to align with their needs $[65,66]$. Also, innovation helps a company avoid competition entering the marketplace, improve its status, and enhance its resilience [11].

Innovation capability significantly mediates dynamic capabilities and competitive advantage. These outcomes are in line with earlier literature. Concurrent investment in exploiting existing product technologies and exploring new product capability will help establish a competitive edge [67]. Exploration and exploration are the most critical innovation capability [68]. Companies maintain competitiveness and success through information and innovation like exploration and exploitation capabilities $[69,70]$.

\subsection{Practical Implication}

One of the major implications for managers and organizations is the dual consideration of exploratory and exploitative product development competencies. As both competencies influence various facets of the new competitive edge along diverse routes, using one kind of expertise to exclude the other will reduce the product creation process efficiency and lead ultimately to poor product results [71]. Excessive exploration at the risk of exploitation can, for instance, in an organization, be expensive because the tangible results of the exploration can only be seen in the near future with significant uncertainty. Concentration on exploitation without testing, on the other hand, prevents the company from learning and growth [72]. Companies should be mindful of limiting their current capacity for product innovation. They should improve competitive stability concerning allocation and coordination of capital, 
which promotes greater exploration of emerging technologies and markets, allowing businesses to flee the trap of competence [73]. Companies must use their dynamic capabilities to build innovations to ensure sustainable results and stay successful. We may infer that businesses can opt for exploitative tactics, such as product quality and innovation, in an increasingly volatile environment, which better shield them from external challenges. These guidelines complement those contended by Kim and Atuahene-Gima [71] that exploitative learning leads to new products' cost-effectiveness under extremely competitive market conditions. Organizations should analyze the conditions of customers, competencies, and technologies. They should improve exploratory abilities with low competition levels or business volatility, enabling them to develop novel radical innovations and establish competitive advantages. Organizations should closely analyze the gaps between the two abilities to leverage their exploratory and exploitative creativity skills and the condition where both of these abilities will build a new product's success story.

\subsection{Limitation and Recommendation}

The research did not involve people outside Ghana. Future research may also be performed to address the limitations described by expanding the research to other settings and countries to achieve an extensive generalization of the analysis. The model could also be evaluated by presenting variables like market orientation as moderator.

\section{REFERENCE}

1. Wogwu, V.E. and D.I. Hamilton, Reconfiguration capability and competitive advantage: A study of Port Harcourt public health sector. Management, 2018. 8(2): p. 4753.
2. Lee, R., J.-H. Lee, and T.C. Garrett, Synergy effects of innovation on firm performance. Journal of Business Research, 2019. 99: p. 507-515.

3. Ferreira, J. and A. Coelho, Dynamic capabilities, innovation and branding capabilities and their impact on competitive advantage and SME's performance in Portugal: the moderating effects of entrepreneurial orientation. International Journal of Innovation Science, 2020.

4. Teece, D.J., G. Pisano, and A. Shuen, Dynamic capabilities and strategic management. Strategic management journal, 1997. 18(7): p. 509-533.

5. Lin, Y. and L.-Y. Wu, Exploring the role of dynamic capabilities in firm performance under the resource-based view framework. Journal of business research, 2014. 67(3): p. 407-413.

6. Khalil, S. and M. Belitski, Dynamic capabilities for firm performance under the information technology governance framework. European Business Review, 2020.

7. Fainshmidt, S., et al., Dynamic capabilities and organizational performance: a metaanalytic evaluation and extension. Journal of Management Studies, 2016. 53(8): p. 13481380.

8. Adeniran, T.V. and K.A. Johnston, Investigating the dynamic capabilities and competitive advantage of South African SMEs. African Journal of Business Management, 2012. 6(11): p. 4088-4099.

9. Li, D.-y. and J. Liu, Dynamic capabilities, environmental dynamism, and competitive advantage: Evidence from China. Journal of business research, 2014. 67(1): p. 2793-2799.

10. Kiiru, G.W., Dynamic capabilities, strategic orientation and competitive advantage of small and medium-retail enterprises in Kenya. 2015.

11. Yousif, A.S.H., F. Rifai, and H. Alhroot, Investigating Relationship of Innovation and Entrepreneurship Adoption Concept and University Competitive Advantage: A Field 
Study. International Journal of Business and Management, 2017. 12(7): p. 138-145.

12. Shmueli, G., et al., Predictive model assessment in PLS-SEM: guidelines for using PLSpredict. European Journal of Marketing, 2019.

13. Hair, J.F., et al., Executing and interpreting applications of PLS-SEM: Updates for family business researchers. Journal of Family Business Strategy, 2020: p. 100392.

14. Ahenkora, K. and E. Adjei, A Dynamic Capabilities Perspective on the Strategic Management of an Industry Organisation. Journal of Management and Strategy, 2012. 3(3): p. 21.

15. Wilden, R. and S.P. Gudergan, The impact of dynamic capabilities on operational marketing and technological capabilities: investigating the role of environmental turbulence. Journal of the Academy of Marketing Science, 2015. 43(2): p. 181-199.

16. Takahashi, A.R.W., et al., Dynamic capabilities, marketing capability and organizational performance. BBR. Brazilian Business Review, 2017. 14(5): p. 466-478.

17. Ferreira, J., S. Cardim, and A. Coelho, Dynamic capabilities and mediating effects of innovation on the competitive advantage and firm's performance: the moderating role of organizational learning capability. Journal of the Knowledge Economy, 2020: p. 1-25.

18. Medeiros, S.A.d., et al., Relationships among dynamic capabilities dimensions in building competitive advantage: a conceptual model. Gestão \& Produção, 2020. 27(1).

19. Chukwuemeka, O.W. and B. Onuoha, Dynamic capabilities and competitive advantage of fast foods restaurants. International Journal of Management Science and Business Administration, 2018. 4(3): p. 714.

20. Karman, A. and A. Savanevičienè, Enhancing dynamic capabilities to improve sustainable competitiveness: insights from research on organisations of the Baltic region. Baltic Journal of Management, 2020.
21. Gonzalez, R.V.D. and T.M. de Melo, The effects of organization context on knowledge exploration and exploitation. Journal of Business Research, 2018. 90: p. 215-225.

22. Khouroh, U., et al., The mediating effect of entrepreneurial marketing in the relationship between environmental turbulence and dynamic capability with sustainable competitive advantage: An empirical study in Indonesian MSMEs. Management Science Letters, 2020. 10(3): p. 709-720.

23. Efrat, K., et al., Leveraging of Dynamic export capabilities for competitive advantage and performance consequences: Evidence from China. Journal of Business Research, 2018. 84: p. 114-124.

24. Jafarinia, S., M.R. Nour Ail, and T. Razmavar, The effects of entrepreneurial orientation and Dynamic Capabilities on firm performance with mediating role of innovation ambidexterity. Innovation Management in Defense Organizations, 2019. 2(1): p. 113-134.

25. Tallott, M. and R. Hilliard, Developing dynamic capabilities for learning and internationalization. Baltic Journal of Management, 2016.

26. Ferreira, J., A. Coelho, and L. Moutinho, Dynamic capabilities, creativity and innovation capability and their impact on competitive advantage and firm performance: The moderating role of entrepreneurial orientation. Technovation, 2020. 92: p. 102061.

27. Wetering, R., P. Mikalef, and A. Pateli, A strategic alignment model for IT flexibility and dynamic capabilities: toward an assessment tool. 2017.

28. Garbellano, S. and M.d.R. Da Veiga, Dynamic capabilities in Italian leading SMEs adopting industry 4.0. Measuring Business Excellence, 2019.

29. Zhang, J. and W.-p. Wu, Leveraging internal resources and external business networks for new product success: A dynamic capabilities perspective. Industrial Marketing Management, 2017. 61: p. 170-181. 
30. Kachouie, R., F. Mavondo, and S. Sands, Dynamic marketing capabilities view on creating market change. European Journal of Marketing, 2018.

31. Molina-Castillo, F.-J., D. Jimenez-Jimenez, and J.-L. Munuera-Aleman, Product competence exploitation and exploration strategies: The impact on new product performance through quality and innovativeness. Industrial Marketing Management, 2011. 40(7): p. 1172-1182.

32. Shanker, R., et al., Organizational climate for innovation and organizational performance: The mediating effect of innovative work behavior. Journal of vocational behavior, 2017. 100: p. 67-77.

33. Cheraghalizadeh, R., The Effect of Innovative Ability on Competitive Performance Through Problem Identification and New Idea Generation. International Journal of Business and Technology Management, 2021. 3(1): p. 55-62.

34. Anwar, M., Business model innovation and SMEs performance-does competitive advantage mediate? International Journal of Innovation Management, 2018. 22(07): p. 1850057.

35. Bhat, S. and K.S. Momaya, Innovation capabilities, market characteristics and export performance of EMNEs from India. European Business Review, 2020.

36. Anning-Dorson, T. and M.B. Nyamekye, Be flexible: turning innovativeness into competitive advantage in hospitality firms. International Journal of Contemporary Hospitality Management, 2020.

37. Vicente, M., J.L. Abrantes, and M.S. Teixeira, Measuring innovation capability in exporting firms: the INNOVSCALE. International Marketing Review, 2015.

38. Urbancova, H., Competitive advantage achievement through innovation and knowledge. Journal of competitiveness, 2013. 5(1).

39. Molina-Morales, F.X., M.T. MartínezFernández, and V.J. Torlò, The dark side of trust: The benefits, costs and optimal levels of trust for innovation performance. Long Range Planning, 2011. 44(2): p. 118-133.

40. Ahakwa, I., et al., The Effects of Job Autonomy, Organizational Learning, and Work Environment on Organizational Commitment of Public Sector Employees in the Ashanti Region of Ghana. International Journal of Scientific Research and Management, 2021. 9(1): p. 2099-2110.

41. Ahakwa, I., et al., The Influence of Employee Engagement, Work Environment and Job Satisfaction on Organizational Commitment and Performance of Employees: A Sampling Weights in PLS path Modelling. SEISENSE Journal of Management, 2021. 4(3): p. 34-62.

42. Thatte, A.A., Competitive advantage of a firm through supply chain responsiveness and SCM practices. 2007, University of Toledo.

43. Hooley, G.J., et al., The performance impact of marketing resources. Journal of business research, 2005. 58(1): p. 18-27.

44. Atuahene-Gima, K., Resolving the capabilityrigidity paradox in new product innovation. Journal of marketing, 2005. 69(4): p. 61-83.

45. Hair Jr, J.F., et al., A primer on partial least squares structural equation modeling (PLSSEM). 2016: Sage publications.

46. Chin, W.W., R.A. Peterson, and S.P. Brown, Structural equation modeling in marketing: Some practical reminders. Journal of marketing theory and practice, 2008. 16(4): p. 287-298.

47. Gokmen, S., R. Dagalp, and S. Kilickaplan, Multicollinearity in measurement error models. Communications in Statistics-Theory and Methods, 2020: p. 1-12.

48. Tackie, E.A., et al., Integration of Economic, Educational and Socio-Cultural Capabilities for Rural Poverty Alleviation in Northern Ghana. Integration, 2020. 5(1).

49. Fornell, C. and D.F. Larcker, Evaluating structural equation models with unobservable variables and measurement error. Journal of marketing research, 1981. 18(1): p. 39-50.

50. Henseler, J., C.M. Ringle, and M. Sarstedt, A new criterion for assessing discriminant validity in variance-based structural equation 
modeling. Journal of the academy of marketing science, 2015. 43(1): p. 115-135.

51. Kline, R.B., Convergence of structural equation modeling and multilevel modeling. 2011: na.

52. Cohen, S., Perceived stress in a probability sample of the United States. 1988.

53. Ahakwa, I., et al., Exploring the Impact of Traditional Communication Channels on Customer Purchase Decision: A Case Study of University Students in Ghana. SEISENSE Business Review, 2021. 1(1): p. 31-44.

54. Lavie, D. and L. Rosenkopf, Balancing exploration and exploitation in alliance formation. Academy of management journal, 2006. 49(4): p. 797-818.

55. Isobe, T., S. Makino, and D.B. Montgomery, Exploitation, exploration, and firm performance: The case of small manufacturing firms in Japan. 2004.

56. Kocoglu, I., et al., Learning, $R \& D$ and manufacturing capabilities as determinants of technological learning: enhancing innovation and firm performance. Procedia-social and behavioral sciences, 2012. 58: p. 842-852.

57. Martínez-Costa, M., D. Jiménez-Jiménez, and H.A. Dine Rabeh, The effect of organisational learning on interorganisational collaborations in innovation: an empirical study in SMEs. Knowledge Management Research \& Practice, 2019. 17(2): p. 137-150.

58. Nielsen, P., et al., Capabilities for innovation: The Nordic model and employee participation. Nordic Journal of Working Life Studies, 2012. 2(4): p. 85-115.

59. Fallon-Byrne, L. and B. Harney, Microfoundations of dynamic capabilities for innovation: a review and research agenda. Irish Journal of Management, 2017. 36(1): p. 21-31.

60. Lisboa, A., D. Skarmeas, and C. Lages, Innovative capabilities: Their drivers and effects on current and future performance. Journal of Business Research, 2011. 64(11): p. 1157-1161.

61. Jeng, D.J.-F. and A. Pak, The variable effects of dynamic capability by firm size: the interaction of innovation and marketing capabilities in competitive industries. International Entrepreneurship and Management Journal, 2016. 12(1): p. 115-130.

62. VU, H.M., A review of dynamic capabilities, innovation capabilities, entrepreneurial capabilities and their consequences. The Journal of Asian Finance, Economics and Business (JAFEB), 2020. 7(8): p. 485-494.

63. Jurksiene, L. and A. Pundziene, The relationship between dynamic capabilities and firm competitive advantage. European Business Review, 2016.

64. Kafetzopoulos, D., K. Gotzamani, and V. Gkana, Relationship between quality management, innovation and competitiveness. Evidence from Greek companies. Journal of Manufacturing Technology Management, 2015.

65. Distanont, A. and O. Khongmalai, The role of innovation in creating a competitive advantage. Kasetsart Journal of Social Sciences, 2018.

66. Anning-Dorson, T., Innovation and competitive advantage creation. International Marketing Review, 2018.

67. Liao, S.-H., D.-C. Hu, and L.-W. Ding, Assessing the influence of supply chain collaboration value innovation, supply chain capability and competitive advantage in Taiwan's networking communication industry. International Journal of Production Economics, 2017. 191: p. 143-153.

68. Tresna, P.W. and S.u.J. Raharja, Effect of entrepreneurial orientation, product innovation and competitive advantage on business performance in creative industries in Bandung City, Indonesia. Review of Integrative Business and Economics Research, 2019. 8: p. 51-60.

69. Chatzoglou, P. and D. Chatzoudes, The role of innovation in building competitive advantages: an empirical investigation. European Journal of Innovation Management, 2018.

70. Amarakoon, U., J. Weerawardena, and M.-L. Verreynne, Learning capabilities, human 
Nana Esi Quagraine et al Int. J. Sci. Res. Comput. Sci. Eng. Inf. Technol, May-June - 2021, 7 (3) : 146-160

resource management innovation and competitive advantage. The International Journal of Human Resource Management, 2018. 29(10): p. 1736-1766.

71. Kim, N. and K. Atuahene-Gima, Using exploratory and exploitative market learning for new product development. Journal of Product Innovation Management, 2010. 27(4): p. 519-536.

72. Auh, S. and B. Menguc, Balancing exploration and exploitation: The moderating role of competitive intensity. Journal of business research, 2005. 58(12): p. 1652-1661.

73. Zhou, K.Z., Innovation, imitation, and new product performance: The case of China. Industrial Marketing Management, 2006. 35(3): p. 394-402.
Cite this article as :

Nana Esi Quagraine, Cai Li, Isaac Ahakwa, Nana Aba Quagraine, "Dynamic Capabilities and Competitive Advantage of Telecommunication Companies in Ghana. The Role of Innovation Capability", International Journal of Scientific Research in Computer Science, Engineering and Information Technology (IJSRCSEIT), ISSN : 2456-3307, Volume 7 Issue 3, pp. 146-160, May-June 2021. Available at doi : https://doi.org/10.32628/CSEIT217314 Journal URL : https://ijsrcseit.com/CSEIT217314 